\title{
Ontogenesis of Prolactin Receptors in the Human Fetus in Early Gestation Implications for Tissue Differentiation and Development
}

\author{
Michael Freemark, ${ }^{\star}$ Phyllis Driscoll, ${ }^{*}$ Rhonda Maaskant, ${ }^{\ddagger}$ Anna Petryk, ${ }^{\star}$ and Paul A. Kelly \\ *Department of Pediatrics and Department of Cell Biology, Duke University Medical Center, Durham, North Carolina 27710; and the \\ ${ }^{\ddagger}$ Institut National de la Santé et de la Recherche Medicalé Unite 344-Endocrinologie Moleculaire, Faculté de Medecine Necker Enfants \\ Malades, 75730 Paris, France
}

\begin{abstract}
To explore potential roles for lactogenic hormones in human fetal development, we examined the distribution and ontogenesis of expression of prolactin receptors (PRLRs) in human fetal tissues at 7.5-14 wk of gestation and in tissues of the embryonic and fetal rat on days e12.5-e20.5. Histochemical analysis of PRLR immunoreactivity in the human fetus and fetal rat revealed novel and unexpected patterns of receptor expression. Most remarkable was the appearance in early fetal development of intense PRLR immunoreactivity in tissues derived from embryonic mesoderm, including the periadrenal and perinephric mesenchyme, the pulmonary and duodenal mesenchyme, the cardiac and skeletal myocytes, and the mesenchymal precartilage and maturing chondrocytes of the endochondral craniofacial and long bones, vertebrae and ribs. Striking changes in the cellular distribution and magnitude of expression of PRLRs were noted in many tissues during development. In the fetal adrenal the initial mesenchymal PRLR expression is succeeded by the emergence of PRLR immunoreactivity in deeper fetal cortical cell layers. In the fetal kidney and lung, the invagination of cortical mesenchyme is accompanied by progressive PRLR immunoreactivity in bronchial and renal tubular epithelial cells. In the pancreas, the PRLR is expressed primarily in acinar cells and ducts in early gestation; in late gestation and in the postnatal period, the PRLR is expressed predominantly in pancreatic islets, co-localizing with insulin and glucagon. Finally in fetal hepatocytes, PRLR immunoreactivity increases significantly between embryonic days e52 and e96 in the human fetus and between days e16.5 and e18.5 in the fetal rat. In addition to playing important roles in reproduction, lactation, and immune function, the lactogenic hormones likely play roles in tissue differentiation and organ development early in gestation. (J. Clin. Invest. 1997. 99:1107-1117.) Key words: placenta $\bullet$ lactogen $\bullet$ embryo $\bullet$ growth $\bullet$ development
\end{abstract}

Address correspondence to Dr. Michael Freemark, Department of Pediatrics, Box 3080, Duke University Medical Center, Durham, NC 27710. Phone: 919-684-3772; FAX: 919-684-8613; E-mail: freem001@ mc.duke.edu

Received for publication 21 October 1996 and accepted in revised form 11 December 1996.

J. Clin. Invest.

(C) The American Society for Clinical Investigation, Inc. 0021-9738/97/03/1107/11 \$2.00

Volume 99, Number 5, March 1997, 1107-1117

\section{Introduction}

Nearly all studies of the biological actions of lactogenic hormones have been conducted in differentiated tissues from neonatal and postnatal animals and human adults. And yet the lactogenic hormones placental lactogen (PL) and prolactin (PRL) ${ }^{1}$ circulate in fetal as well as postnatal serum (1-7) and bind with high affinity to mammalian fetal tissues in mid- and late gestation $(4,6,8-11)$, during periods of active tissue differentiation, growth, and maturation.

The roles of the lactogens in tissue differentiation and development are largely unexplored. We reasoned $(a)$ that studies of the distribution of lactogenic receptors in embryonic and fetal tissues would yield insight into the roles of lactogens in tissue differentiation and growth; and $(b)$ that changes in the distribution of receptors within a single tissue during ontogeny would implicate changing roles for lactogens in organ development and function.

To explore potential roles for lactogenic hormones in human fetal development, we examined the distribution and ontogenesis of expression of prolactin receptors (PRLRs) in selected human fetal tissues at 7.5-14 wk of gestation. Changes in the expression and distribution of PRLRs in the human fetus during ontogeny were compared with changes in PRLR expression in the fetal rat between embryonic days e12.5 and e20.5.

\section{Methods}

Materials. Moloney murine leukemia virus reverse transcriptase and dithiothreitol were purchased from Gibco-BRL (Gaithersburg, MD) while deoxynucleotide triphosphates, RNAse inhibitor, random hexamer oligonucleotides, polynucleotide kinase and restriction enzymes, and the Expand High Fidelity Taq polymerase were purchased from Boehringer Mannheim Biochemicals (Indianapolis, IN). Oligonucleotides were synthesized and purified by the Duke University DNA synthesis facility. ZetaProbe membranes were purchased from Bio-Rad Corporation (Hercules, CA). $\left.{ }^{[32} \mathrm{P}\right] \mathrm{dCTP}$ was obtained from Amersham Corp. (Arlington Heights, IL). A Sequenase DNA Sequencing Kit was purchased from US Biochemical Corp. (Cleveland, $\mathrm{OH}$ ). DNase free RNase A, RNase free DNase 1, Digoxeginin labeling kits and Nucleic acid detection kits were purchased from Boehringer Mannheim Biochemicals. A polyclonal antisera to human insulin was purchased from Vector Laboratories, Inc. (Burlingame, CA). A polyclonal antiserum to porcine glucagon was prepared by Dr. Roger Unger (University of Texas Southwestern, Dallas, TX). Unless specifically noted, all other chemicals and chemical reagents were from Sigma Chemical Co. (St. Louis, MO). A Vectastain ABC kit was purchased from Vector Laboratories, Inc.

Purified human placental lactogen, human and rat prolactin, and

1. Abbreviations used in this paper: PRL, prolactin; PRLR, prolactin receptor. 
rat growth hormone were obtained from the National Institute of Arthritis, Diabetes, and Digestive Kidney Diseases.

Human and rat fetal tissues. Human fetal tissues were obtained from the Central Laboratory for Human Embryology at the Department of Pediatrics, University of Washington School of Medicine (Seattle, WA). Fetal tissues were retrieved following elective termination of pregnancy by dilatation and curettage. In all cases the informed consent of the mother was obtained prior to procurement of the tissues, in accordance with guidelines outlined by the Duke University Instituitional Review Board. The tissues were dissected rapidly and fixed for 20-24 h in ice-cold Bouin's solution and were then washed extensively in cold $70 \%$ ethanol prior to embedding in paraffin. The gestational age of each fetus was estimated by measurement of foot length, as described by Shepard (12). This method assigns the day of the mother's last menstrual period as day 14 of gestation. At least three samples of each fetal tissue at each gestational age were analyzed, and each group of tissues included at least one male and one female.

Fetal rat tissues were obtained by two methods. First, timed-pregnant Sprague Dawley rats on days 12.5 (day of appearance of the vaginal plug equals day 0.5) through 20.5 were purchased from Zivic Miller Laboratories (Zelienople, PA). As approved by the Duke University Committee on Animal Welfare, pregnant rats were killed by cervical dislocation following a brief period of carbon dioxide anesthesia. Fetal rats were immersed immediately in $4 \%$ paraformaldehyde or in Bouin's solution. After fixation for $24 \mathrm{~h}$ at $4^{\circ} \mathrm{C}$, the tissues were embedded in paraffin, rehydrated, sectioned at 5-7 $\mu \mathrm{m}$ and placed on Superfrost Plus slides (Sigma Chemical Co.). At least three fetal rats were analyzed at each gestational age. After embryonic day 17.5, when the gender of the fetuses could be determined readily, the sex of each fetus was noted, and at least one male and one female fetus were examined at each day in late gestation.

Additional paraffin-embedded fetal tissue sections were purchased from Novagen, Inc. (Madison, WI). The Novagen, Inc. sections were prepared from tissues processed in a manner similar to those processed in our laboratory and the results of studies using tissue sections from both sources were similar or identical.

Reverse transcription-PCR. Reverse transcription-PCR (RT-PCR) was employed to examine the expression of the human PRLR (hPRLR) in human fetal tissues. Complementary DNA was generated under the following conditions: $5 \mu \mathrm{g}$ of total RNA from each tissue was incubated for $60 \mathrm{~min}$ at $37^{\circ} \mathrm{C}$ with $200 \mathrm{U}$ of Moloney murine leukemia virus reverse transciptase in buffer $(20 \mathrm{mM}$ Tris $\mathrm{HCl}, \mathrm{pH}$ 8.3 , containing $50 \mathrm{mM} \mathrm{KCl}$, and $5 \mathrm{mM} \mathrm{MgCl}_{2}$ ) with $1 \mathrm{mM}$ of each deoxynucleotide triphosphate, $30 \mathrm{U}$ of RNAse inhibitor, $10 \mathrm{mM}$ dithiothreitol, and $1 \mu \mathrm{g}$ random hexamer oligonucleotides in a total volume of $30 \mu \mathrm{l}$. Two control experiments were performed: in the first, tissue RNA was incubated in buffer containing dNTPs, RNAse inhibitor, dithiothreitol and random hexamers but no reverse transcriptase; in the second, samples containing buffer but no RNA were incubated with dNTPs, RNAse inhibitor, dithiothreitol and random hexamers in the presence of reverse transcriptase. One-fifth of the complementary DNA generated under these conditions (equivalent to $1 \mu \mathrm{g}$ of total RNA from each tissue) was amplified by PCR. Prior to amplification, the cDNA was heated at $95^{\circ} \mathrm{C}$ for $4-4.5 \mathrm{~min}$ and quickly cooled on ice. The cDNA was then amplified for 30 cycles with $1 \mathrm{U}$ of Taq polymerase in buffer $(18.6 \mathrm{mM}$ Tris $\mathrm{HCl}, \mathrm{pH} 8.3$, containing $45.9 \mathrm{mM} \mathrm{KCl}$ and $2.2 \mathrm{mM} \mathrm{MgCl} 2$ ) with $0.2 \mathrm{mM}$ deoxynucleotide triphosphates and $25 \mathrm{pmol}$ each of two oligonucleotide primers (final concentration $0.5 \mu \mathrm{M}$ in a total volume of $50 \mu \mathrm{l}$ ) encoding portions of the human prolactin receptor. Samples were denatured at $94^{\circ} \mathrm{C}$ for $30 \mathrm{~s}$, annealed at $53^{\circ} \mathrm{C}$ for $1 \mathrm{~min}$ and extended at $72^{\circ} \mathrm{C}$ for 1 $\mathrm{min}$; the final reaction volume was $50 \mu \mathrm{l}$.

Sense primer 1 was a 22 mer (5'AGATCTTTAAATGTCGTTCTCC3') encoding nucleotides 378-399 of the extracellular domain of the human prolactin receptor (13). Antisense primer 1 (5'TAATCGAATTTCATACAGGAGC3') was a 22 mer encoding a downstream portion (nucleotides 779-800) of the extracellular do- main. Sense primer 2 was a 20 mer (5'GTCTCCACCTACCCTGATTG3') encoding nucleotides 737-756 of the hPRLR extracellular domain, while antisense primer 2 was an 18 mer (5'CGGAAAGATGCAGGTCAC3') encoding nucleotides 1074-1091 in the cytoplasmic domain. Primers encoding human cyclophilin antisense ( $5^{\prime}$ GATCTTCTTGCTGGTCTT3') were used in parallel studies to confirm the integrity of the cDNA; the sense primer 5'AGGGTTTATGTGTCAGGG3' encodes nucleotides 174-191 of the 708 bp human cyclophilin, and the antisense primer 5'GATCTTCTTGCTGGTCTTG3' encodes nucleotides 450-468.

After amplification by PCR, one-fourth volume (12.5 $\mu \mathrm{l})$ of each sample was electrophoresed through $2 \%$ agarose gels containing 5 $\mu \mathrm{g} / \mathrm{ml}$ ethidium bromide. The DNA was then transferred to Zeta probe membranes in $0.4 \mathrm{~N} \mathrm{NaOH}$. After neutralization in $2 \times \mathrm{SSC}$ $(0.3 \mathrm{M} \mathrm{NaCl}, 0.03 \mathrm{M} \mathrm{Na}$ citrate, $\mathrm{pH} 7.0)$, the membranes were baked at $80^{\circ} \mathrm{C}$ for $2 \mathrm{~h}$ and stored at room temperature. For Southern analysis, a 19 mer oligonucleotide (5'ATCTGTTTGATTATTGTCT3') encoding a portion (nucleotides 1026-1044) of the transmembrane domain of the human prolactin receptor was radiolabeled by phosphorylation to a specific activity of $3.6 \times 10^{9} \mathrm{cpm} / \mu \mathrm{g}$ using T4 polynucleotide kinase. The Zeta probe membranes were prehybridized for $2 \mathrm{~h}$ at $55^{\circ} \mathrm{C}$ in $20 \mathrm{mM} \mathrm{NaH} \mathrm{PO}_{4}, \mathrm{pH} 7.0$, containing $10 \times$ Denhardt's reagent $(0.2 \%$ Ficoll, $0.2 \%$ polyvinylpyrrolidone, $0.2 \%$ BSA Fraction V), $7 \%$ SDS, $5 \times$ SSC and $100 \mu \mathrm{g} / \mathrm{ml}$ denatured salmon sperm DNA (Sigma Chemical Co.). The radiolabeled oligonucleotide was then added to the prehybridization mixture at a final concentration of $750,000 \mathrm{cpm} / \mathrm{ml}$, and the blots were hybridized at $55^{\circ} \mathrm{C}$ for $16-18 \mathrm{~h}$. The blots were washed at $55^{\circ} \mathrm{C}$ with $6 \times \mathrm{SSC}, 0.1 \% \operatorname{SDS}(15 \mathrm{~min} \times 2)$, $2 \times \operatorname{SSC}, 0.1 \% \operatorname{SDS}(15 \mathrm{~min} \times 2)$, and $1 \times \operatorname{SSC}, 0.1 \% \operatorname{SDS}(5 \mathrm{~min} \times 2)$ and were apposed to photographic film at $-70^{\circ} \mathrm{C}$ for autoradiography. Control experiments using no RNA in reverse transcriptions and no cDNA in PCR amplifications produced no radiographic signal following hybridization with ${ }^{32} \mathrm{P}$-labeled oligonucleotide probes.

In order to determine the nucleotide sequence of the lactogenic receptor expressed in human fetal tissues, PCR products were subcloned into the TA cloning vector (InVitroGen Corp., San Diego, CA) and were sequenced using the dideoxy chain termination method (14).

Immunohistochemistry. Immunohistochemical studies were performed using methods similar to those described in detail in previous manuscripts $(15,16)$. Briefly, paraffin sections were deparaffinized, hydrated, and incubated in methanol containing $1 \% \mathrm{H}_{2} \mathrm{O}_{2}$ for $10 \mathrm{~min}$ at room temperature. Nonspecific sites were blocked in $5 \%$ horse serum and $5 \%$ nonfat milk for $2 \mathrm{~h}$. Tissue sections were then incubated for $19-24 \mathrm{~h}$ at $4^{\circ} \mathrm{C}$ with monoclonal antibodies to the PRLR (10-50 $\mu \mathrm{g} / \mathrm{ml}$ ) in PBS containing $0.34 \mathrm{M} \mathrm{NaCl}$ and $2 \%$ horse serum. Two monoclonal anti-PRLR antibodies (U5 and U6) were used; both antibodies react with regions of the rat PRLR protein distinct from that region which binds lactogenic hormones (17). Consequently, these monoclonal antibodies can detect both "free" (unoccupied) PRLR protein as well as receptor protein that is bound to endogenous lactogenic hormones such as human placental lactogen. After the overnight incubation, the slides were incubated with biotinylated horse anti-mouse IgG (rat absorbed, $5 \mu \mathrm{g} / \mathrm{ml}$ ) in PBS/ $0.5 \mathrm{M} \mathrm{NaCl} / 2 \%$ horse serum for $4 \mathrm{~h}$ at room temperature. The slides were then washed and incubated with the Vectastain $\mathrm{ABC}$ reagent (Vector Laboratories, Inc.) for $30 \mathrm{~min}$ at room temperature, washed, and incubated in diaminobenzidine coloring solution $(50 \mathrm{mM}$ Tris, $\mathrm{pH} 7.5$, containing $0.006 \% \mathrm{H}_{2} \mathrm{O}_{2}$ and $200 \mu \mathrm{g} / \mathrm{ml}$ of diaminobenzidine tetrahydrochloride) in the dark for 10-20 min to detect the antibody-bound PRLR.

Several controls were employed to ensure the specificity of immunoreactive staining. First, there was no immunoreactive staining of tissues: $(a)$ when primary antibody was omitted from the incubation medium; or $(b)$ when tissues were incubated with pre-immune mouse serum $(2 \%)$, ascites fluid $(2 \%)$ or purified mouse IgG $(20-100 \mu \mathrm{g} / \mathrm{ml})$ rather than monoclonal anti-rat PRLR antibody. Second, the intensity of immunoreactive staining was reduced markedly when primary antisera were preincubated (absorbed) with highly purified rat liver 
prolactin receptor, as described previously (15), or with human prolactin binding protein(s) that had been purified from the conditioned media of cells transfected stably with a cDNA encoding the human PRL binding protein (below). The intensity of immunostaining was determined by analysis of photographs of the stained sections. For purposes of comparison, individual sections were prepared, incubated, developed, and photographed under identical conditions. The photographs were then scanned with a Hewlett Packard desktop scanner and the intensity of staining was quantified by densitometric analysis using the Sigma Scan software (Menlo Park, CA). Results are presented as the mean $\pm \mathrm{SE}$ of at least three separate experiments.

In selected experiments, the cellular distribution of PRLR immunoreactivity in fetal pancreas was compared with that of insulin or glucagon. To determine the cellular distribution of insulin and glucagon immunoreactivity, sections of human fetal pancreas were processed in the manner described previously and were incubated with polyclonal antisera/human insulin (1:50) or porcine glucagon (1:2500) in PBS containing $0.35 \mathrm{M} \mathrm{NaCl}$ and $2 \%$ horse serum. Following an overnight incubation for $20 \mathrm{~h}$ at $4^{\circ} \mathrm{C}$, these sections were washed with PBS and then incubated for $60 \mathrm{~min}$ at room temperature with peroxidase-labeled anti-rabbit IgG. After extensive washing with PBS, the immunoreactive staining was developed with diaminobenzidine, as described above.

Purification of human PRL binding proteins and preabsorption of anti-PRLR antisera. Human PRL binding proteins were purified from the conditioned media of human 293 fibroblasts transfected stably with a construct containing the signal peptide of the rat PRLR coupled to the mature region of the human PRLR (18). The signal peptide of the rat PRLR was utilized to form the construct because its expression in transfected cells exceeds that of the human PRLR signal peptide. The construct includes a stop codon at position 211 of the mature receptor, so that the 210 extracellular residues are expressed as a secreted protein. This produces a glycosylated extracellular domain of the human PRLR that is secreted into cellular conditioned media.

PRL binding proteins in the cellular conditioned media were purified $\sim 3,000$-fold by affinity chromatography using a column of bovine prolactin coupled to Affi-Gel 10, as described previously (15). Electrophoretic analysis of the Affi-Gel eluate under reducing conditions revealed a major protein with apparent $M_{\mathrm{r}} 36,000$. The purified PRL BP(s) bound radiolabeled human PL and human PRL with high affinity $\left(K_{\mathrm{d}} 0.5-2 \mathrm{nM}\right)$ and on Western blots reacted specifically with antisera U5 and U6 $(1 \mu \mathrm{g} / \mathrm{ml})$ but not with purified mouse IgG.

For studies of the specificity of immunostaining, the anti-PRLR antiserum (final concentration $40 \mu \mathrm{g} / \mathrm{ml}$ ) was preincubated overnight at $23^{\circ} \mathrm{C}$ in PBS containing purified PRL BP(s) $(\sim 10 \mu \mathrm{g}$ protein $/ \mathrm{ml})$. In parallel control studies the antisera were preincubated in PBS containing $100 \mu \mathrm{g} / \mathrm{ml} \mathrm{BSA}$. The mixtures were applied directly to tissue sections in the presence of $2 \%$ horse serum. The intensity of staining with antisera that had been preincubated with PRL binding proteins was compared with the intensity of staining with antisera that had been preincubated with BSA.

\section{Results}

In preliminary experiments we examined the expression of PRLR messenger RNA (mRNA) in human fetal tissues using RT-PCR. PCR primers were selected to encode portions of the extracellular, transmembrane, and cytoplasmic domains of the human PRLR. As shown in Fig. 1, mRNA encoding the membrane-bound PRLR was expressed in diverse tissues of the human fetus as early as $52 \mathrm{~d}(7.5 \mathrm{wk})$ of gestation. The identity of this PRLR mRNA was confirmed by Southern blotting and by nucleotide sequencing.

To localize the expression of the PRLR at the cellular level we used immunohistochemistry, employing two distinct mono- clonal antibodies (U5 and U6) to the rat PRLR. The antibodies gave similar or identical results, though staining with U5 was more intense than staining with $\mathrm{U} 6$ at the concentrations used. The specificity of immunoreactive staining was confirmed in parallel studies in which the antisera were pre-absorbed with PRLR proteins that were purified from the conditioned medium of 293 fibroblasts transfected with a cDNA encoding a soluble human PRL binding protein (Fig. 2). Previous studies $(6,15,16)$ showed that the cellular distribution of PRLR immunoreactivity is similar or identical to the cellular distribution of PRLR mRNA (as determined by in situ hybridization) and colocalizes with placental lactogen binding activity, indicating that immunoreactive PRLR protein is localized at sites of expression of a PRLR message that encodes a functional lactogen binding site.

Our initial studies examined the expression of PRLRs in the fetal liver and small intestine. In the human fetal liver, PRLR immunoreactivity is detected in hepatocytes but not in hematopoietic cells. Staining is most intense in hepatocytes surrounding the central veins. PRLR immunoreactivity can be detected as early as $52 \mathrm{~d}$ of gestation (earliest time point studied), but the intensity of staining increases 2.6 \pm 0.5 -fold (mean \pm SEM, $n=3$ ) during the subsequent $6 \mathrm{wk}$ of pregnancy (Fig. 3). The induction of hepatic PRLR expression in the human fetus during early-mid gestation is paralleled by changes

PRLR mRNA
in the Human Fetus:
RT-PCR

Figure 1. Expression of PRLR mRNA in human fetal tissues in early gestation. On the left is a schematic diagram of the human prolactin receptor (hPRLR), with the location of the PCR products produced by sense and antisense primers 1 and 2 . Note that the PCR products encode portions of the extracellular, transmembrane (TM) and cytoplasmic domains. The figure on the right shows an ethidium bromidestained gel of the PCR product ( $355 \mathrm{bp}$ ) generated with sense and antisense primers 2 . Numbers in parentheses represent days of gestation. In the lane labeled $-R T$, fetal liver RNA was incubated without reverse transcriptase during generation of cDNA. PCR products $(423$ bp) were generated using sense and antisense primers 1 , with results similar to those observed using primers 2 . PCR products encoding cyclophilin were generated (15) from all tissues except those in which cDNA was prepared in the absence of reverse transcriptase. The various PCR products on the gel shown above hybridized specifically to an internal oligonucleotide encoding a portion of the TM domain, and nucleotide sequencing of both the 355 and $423 \mathrm{bp} \mathrm{PCR} \mathrm{products}$ confirmed the identity of the fetal PRLR. 

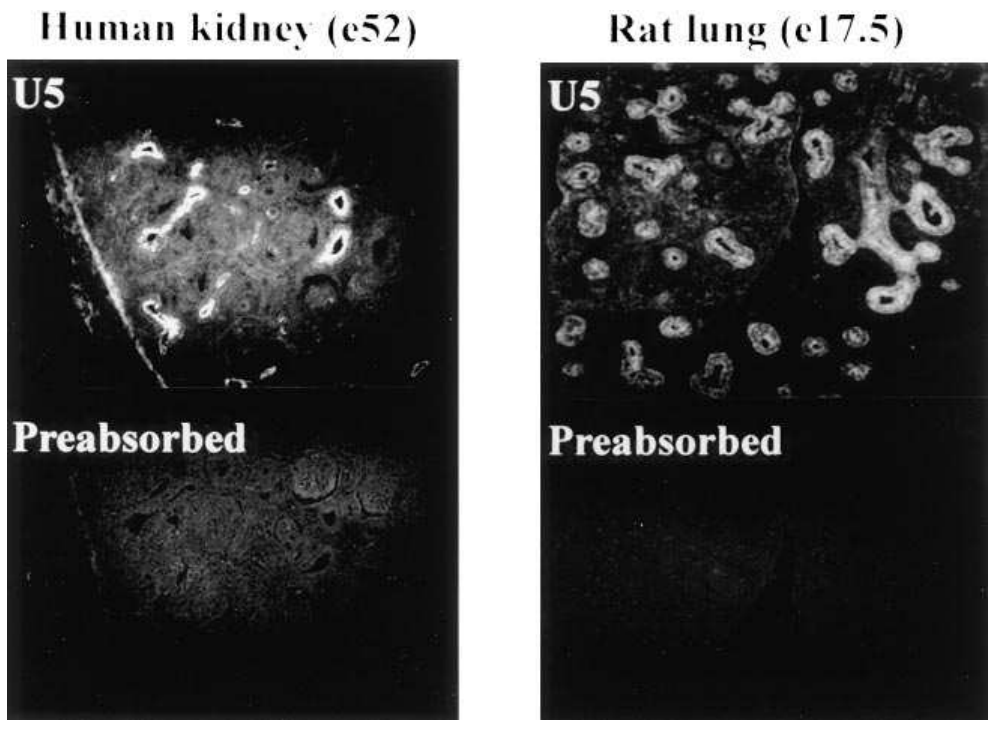

Figure 2. Specificity of immunoreactive staining. Tissue sections were stained with antisera U5 that had been preincubated with BSA (top) or with antisera U5 that had been preincubated with PRL binding proteins that had been purified from maternal rat liver (rat lung section, bottom) or from the conditioned medium of 293 fibroblasts transfected stably with a cDNA encoding a soluble hPRL binding protein (human fetal kidney section at bottom). In this and all subsequent figures, the sections were photographed in dark-field, so that positive staining is shown in white. Similar findings were noted in three experiments using sections of human fetal pancreas and liver and fetal rat liver. $\times 40$.

in the fetal rat during late pregnancy: PRLR immunoreactivity in fetal rat hepatocytes is first noted on day 16.5 and increases strikingly during the next $2 \mathrm{~d}$ of gestation (Fig. 3).

The fetal liver develops from an endodermal diverticulum that buds from the duodenum. In the human fetal duodenum at 12-14 wk of gestation, the PRLR is expressed in villous columnar epithelial cells, particularly at the luminal surface, and in basilar crypts (Fig. 4). In the duodenum of the fetal rat (Fig. 4), the PRLR appears first on day 16.5; PRLR immunoreactivity is detected on the luminal surface of the gut tube, which is composed of four to six layers of stratified epithelial cells. During the next $48-72 \mathrm{~h}$, there is folding of the duodenal epithelium associated with invagination of mesenchyme; this process leads to the formation of well-differentiated villi, each containing a mesenchymal core covered by a single layer of columnar epithelial cells. The progressive maturation and growth of the duodenal mucosa during late gestation are accompanied by a striking increase in PRLR immunoreactivity, which localizes to villous epithelial cells and, to a lesser extent, to mesenchymal cells lining the basal aspect of the mucosa.

The primitive duodenum gives rise to the pancreas as well as the liver. In human adults and postnatal rats PRLRs are detected in pancreatic beta and alpha cells, and there is little or no expression in pancreatic ducts or acinar cells $(19,20)$. But this is not the case in the fetus. Fig. 5 shows sections of human and rat fetal pancreas probed with antisera to the PRLR and to insulin and glucagon. In the human fetus, PRLR immunoreactivity is most intense in pancreatic ducts and acinar cells which express neither insulin nor glucagon. The immunoreactive staining in pancreatic acinar cells is heterogeneous, with some cells staining intensely and others reacting weakly or not at all. In the pancreatic ducts, PRLR immunoreactivity ap-

\section{Ontogeny of Hepatic PRLRs}
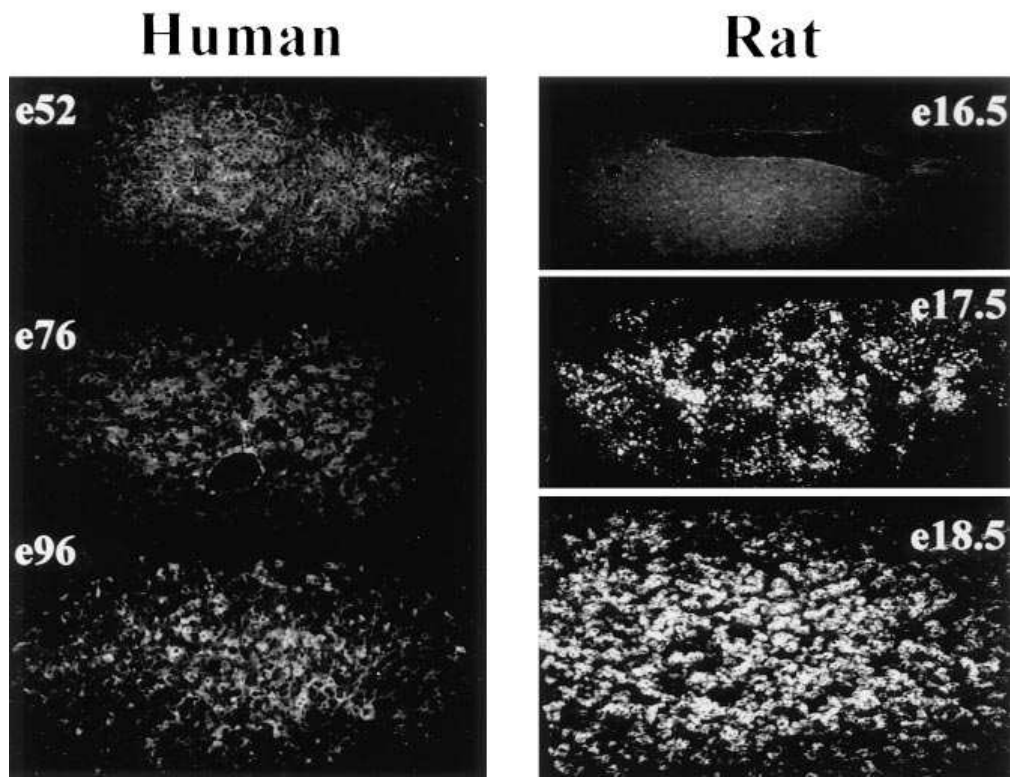

Figure 3. Ontogenesis of PRLR immunoreactivity in human and fetal rat liver. Tissue sections were prepared, incubated, stained and photographed under identical conditions. Anti-PRLR antisera U5 was used at a concentration of $25 \mu \mathrm{g} / \mathrm{ml}$. Control sections incubated with anti-mouse IgG were immunonegative. Similar findings were noted in three separate experiments. Magnification $\times 100$. 


\section{Duodenal Prolactin Receptors}
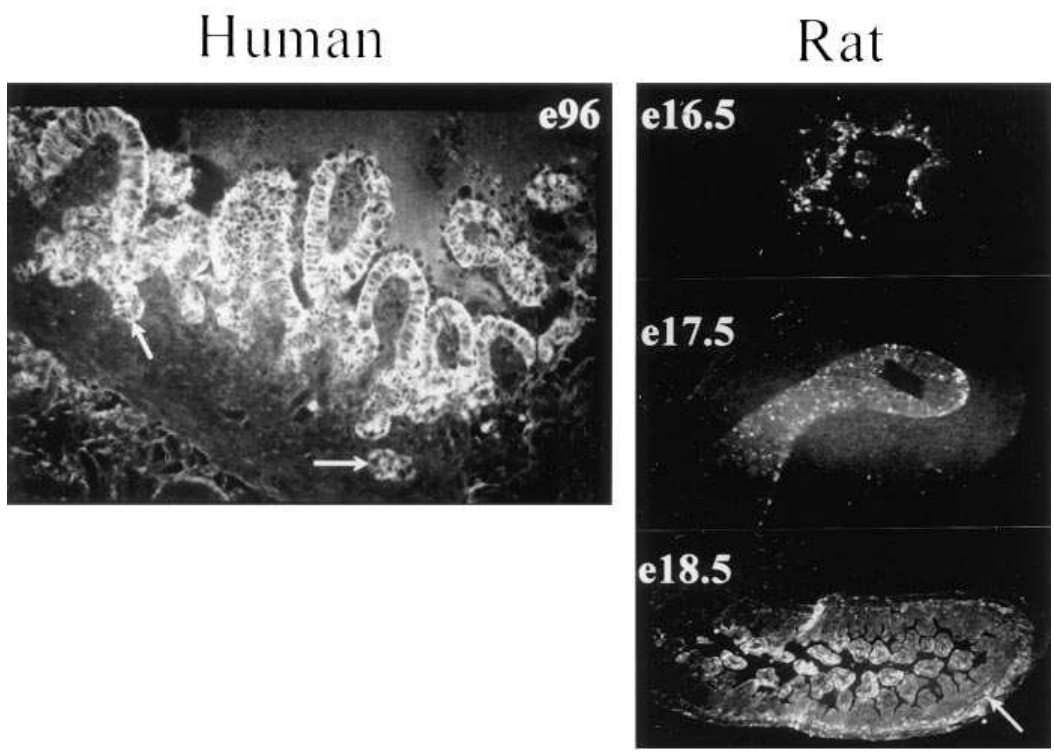

Figure 4. Ontogenesis of PRLR immunoreactivity in human and rat fetal duodenum. Tissue sections were incubated with U5 at concentrations ranging from $20-40 \mu \mathrm{g} / \mathrm{ml}$; control sections were immunonegative. In the human sections, note the prominent staining of duodenal villi and crypts (arrows). In the rat sections, note the staining of duodenal villi and on day e18.5, basilar mesenchyme (arrow). Similar findings were noted in three experiments. $\times 100$.

pears most intense at the luminal surface. In contrast to findings in the human adult, there is only weak staining of pancreatic beta (insulin positive) and alpha (glucagon positive) islet cells in the human fetus in early gestation.

Similar findings are noted in the fetal rat (Fig. 5). On embryonic days $16.5-17$, PRLR immunoreactivity predominates in the pancreatic ductules and acinar tissue. However, by days e18.5-e20.5, the PRLR is expressed in developing islets that arise and bud from the pancreatic ducts. These ontogenetic changes in the distribution of PRLR expression suggest that the roles of lactogenic hormones in pancreatic growth and function may change during development.
Studies of the ontogeny of PRLR expression in other tissues provide additional evidence for changing roles for lactogenic hormones in organ development and function. For example, in the adrenal glands of postnatal rats and human adults, PRLRs are expressed thoughout the cortex (21-23), where lactogens regulate the production of glucocorticoids, and in the human adrenal androgens (23-26). In contrast, in the human fetus at 7.5 wk of gestation (Fig. 6), PRLR immunoreactivity is detected only in a thin rim of capsular-like mesenchymal cells and neocortical-like parenchymal cells lying at or near the surface of the gland. A striking change in PRLR distribution then ensues; by 14 wk of gestation, the PRLR is

\section{PRLRs in the Fetal Pancreas}

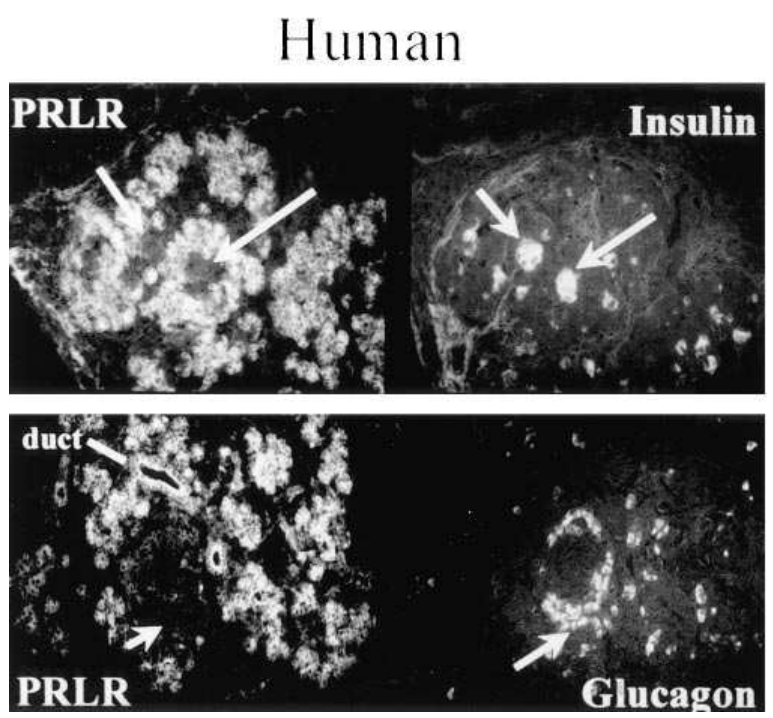

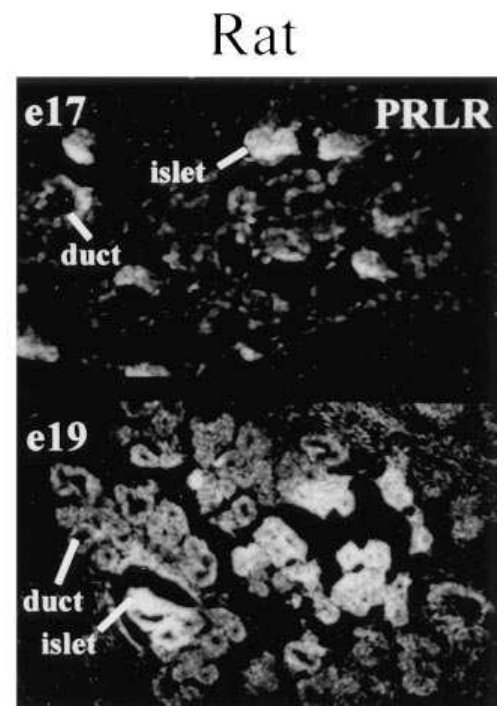

Figure 5. PRLR immunoreactivity in human and fetal rat pancreas. Serial sections of human fetal pancreas (e96) were incubated with anti-PRLR antisera U5 or anti-insulin antisera. In parallel experiments, serial sections were incubated with U5 or with antiglucagon antisera. In the human sections $(\times 100)$ stained with U5, the arrows point to cells that express insulin (top) or glucagon (bottom). Note the intense PRLR immunoreactivity in human fetal pancreatic ductules $(d u c t)$ and in exocrine tissue. In fetal rat sections stained with $\mathrm{U} 5$, note the staining of pancreatic ductules and islets budding from the ducts. $\times 100$. Similar findings were noted in five separate experiments. In all experiments, control sections incubated with anti-mouse $\mathrm{IgG}$ or with U5 that had been preincubated with purified PRL BPs were immunonegative. 


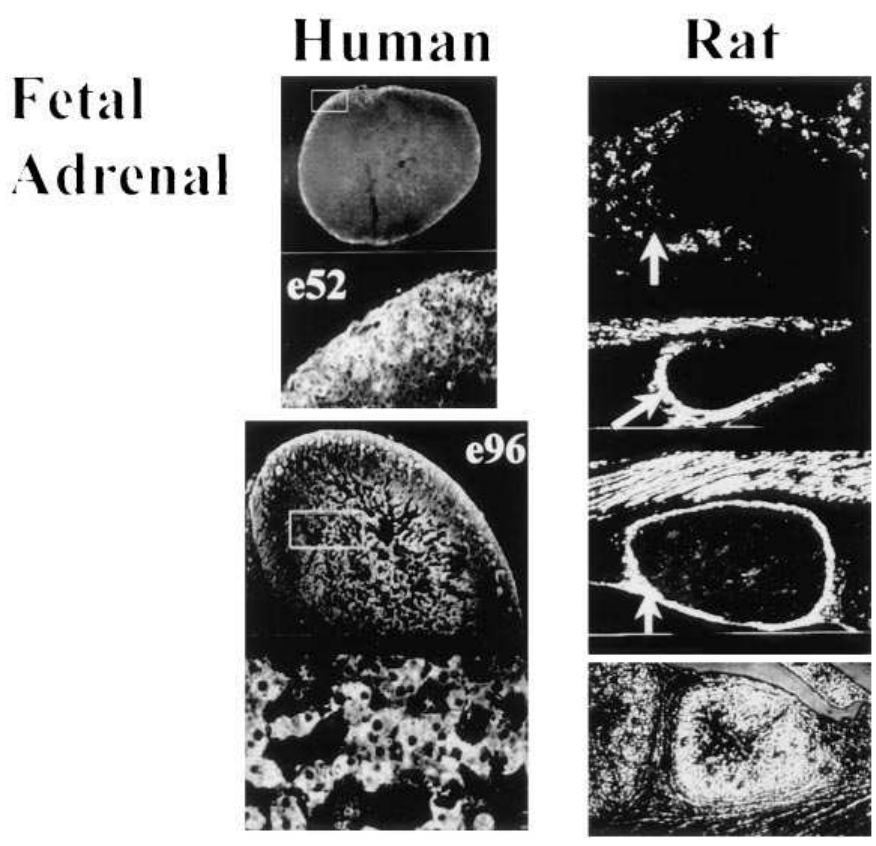

e 15.5

c16.5 Figure 6. Ontogenesis of PRLR immunoreactivity in the human and rat fetal adrenal. Tissue sections were incubated with U5; control sections were immunonegative. In the human sections, note the localization of PRLR immunoreactivity to a rim of mesenchymal and neocortical-

c18.5 like cells on e52; the boxed area is shown at higher magnification below $(\times 100)$. By day e96, PRLR immunoreactivity is detected in centrally-located fetal cortical cells, shown at higher magnification $(\times 200)$ below. In the rat sections note that PRLR immunoreactivity is confined to periadrenal mesenchymal cells (arrows) until c20.5 late in gestation, when abundant cortical reactivity is noted (e20.5). Similar findings were noted in four separate experiments. expressed in fetal cortical cells as well as in the definitive neocortex.

This pattern of change in receptor distribution bears similarities to changes noted in the fetal rat (Fig. 6). On embryonic days $15.5-18.5$ the PRLR is expressed primarily in the dorsal mesenchyme surrounding the adrenal primordium. 1-2 d later, there is intense staining throughout the adrenal cortex, with lesser staining of the mesenchymal capsule and little or no reactivity in medullary cells.

The adrenal mesenchyme and cortical cells arise from coelomic mesothelium, which is derived from intermediate mesoderm. The intermediate mesoderm also gives rise to the renal collecting system. In the human fetal kidney at 7.5-14 wk of gestation (Fig. 7), PRLRs are expressed prominently in col- lecting ducts and tubules and in the renal calyces. These structures are derived from progressive branching of the mesodermal ureteric bud. PRLR expression is particularly prominent at the luminal surfaces of the renal tubules and collecting ducts, consistent with effects of lactogens on renal electrolyte and mineral transport in postnatal animals. PRLR immunoreactivity is also detected in the perinephric mesenchyme that overlies the renal cortex and, to a lesser extent, in the renal capsule. In contrast the glomeruli, which are derived from the metanephric blastema, are immunonegative.

In the fetal rat kidney, PRLR immunoreactivity is first detected on day 16.5 in the perirenal mesenchyme and in metanephric tubules situated centrally in the region of the future renal pelvis. Between embryonic days e16.5 and e19.5, the renal

\section{Ontogenesis of Renal Prolactin Receptors}

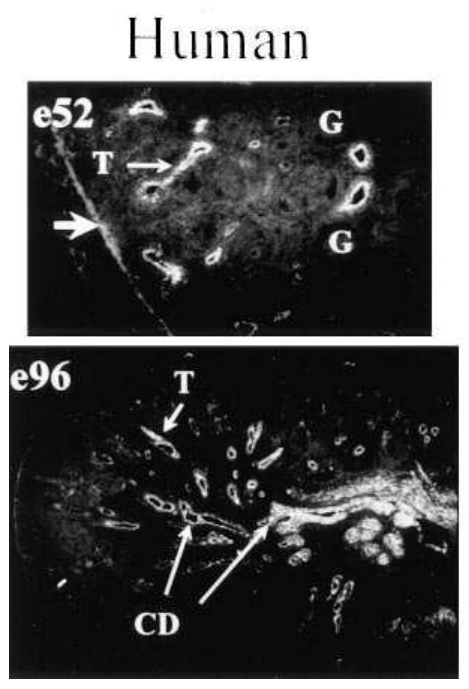

Rat

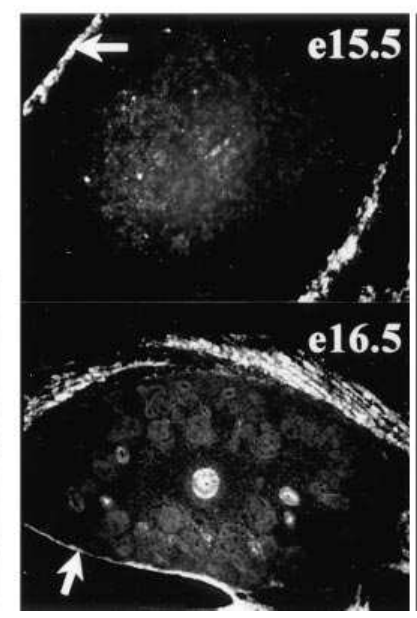

Figure 7. Ontogenesis of PRLR immunoreactivity in the human and rat fetal kidney. Tissue sections were incubated with U6 $(40 \mu \mathrm{g} / \mathrm{ml})$; control sections were immunonegative. In the human sections, note the intense staining of renal tubules $(T)$, collecting ducts and collecting tubules $(C D)$ and calyces, particularly at the luminal surfaces. Note also the staining of the perinephric mesenchyme (thick arrow), particularly on embryonic day e52. Glomeruli $(G)$ were immunonegative. In the fetal rat sections, note the staining of the perinephric mesenchyme on day e15.5 and e16.5 (arrows), the epithelium of the renal pelvis and the peritubular mesenchyme on day e18.5 and the renal tubules $(T)$ on day e20.5. Similar findings were noted in three separate experiments. $\times 40$. 
Ontogenesis of PRLRs in Human Lung

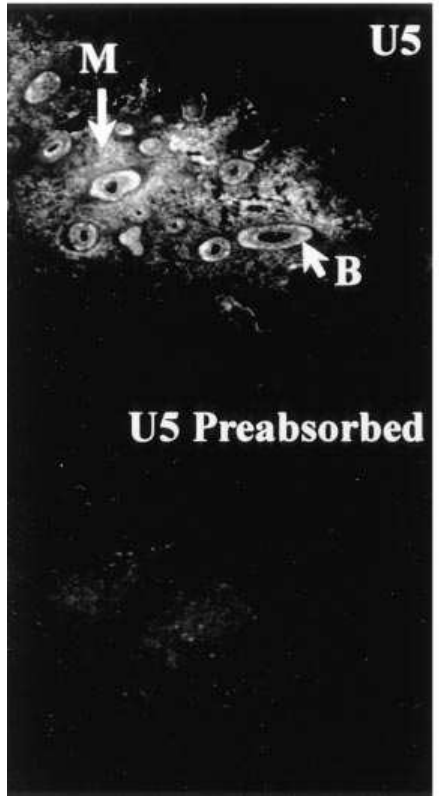

Figure 8. Ontogenesis of PRLR immunoreactivity in the human fetal lung. Tissue sections were incubated with U5 $(25 \mu \mathrm{g} / \mathrm{ml})$; control sections were immunonegative. In the human sections note the staining of pulmonary mesenchyme $(M)$ and the bronchial $(B)$ airway epithelium, where staining is most intense in the basilar cells on day e57 and in the luminal surface epithelial cells on day e96. pelvis enlarges markedly and the number of medullary collecting ducts increases strikingly, with a corresponding reduction in nephric mesenchyme (27). During these later stages of rat pregnancy, the PRLR is expressed prominently in the perirenal and nephric mesenchyme and in medullary collecting ducts and renal tubules. By day e20.5, tubules in the renal cortex become immunoreactive. As in the human fetal kidney, glomeruli in the kidney of the fetal rat are immunonegative.

Mesoderm plays a central role in the development of the lung as well as the adrenal and kidney. The fetal lung develops when tubular outpockets of pharyngeal endoderm invade mesenchyme derived from splanchnic mesoderm (28). As in the adrenal and kidney, the PRLR in the lung is expressed prominently in mesenchymal tissue during early fetal development. In the human fetal lung at $7.5 \mathrm{wk}$ of gestation (Fig. 8) the PRLR is expressed in the pulmonary mesenchyme and in the tubular airways, which are lined by a simple cuboidal epithelium. At this stage of development, staining of the airways appears most intense at the base of the cuboidal epithelium. Subsequently, by 11-14 wk of gestation, the branching epithelium is stained most prominently at the luminal borders, and PRLR immunoreactivity in the pulmonary mesenchyme is intense.
The pattern of PRLR expression in the fetal rat lung (Fig. 9) is similar to that in the human fetal lung. On embryonic day 13.5, PRLR immunoreactivity is detected in the surface mesenchyme of the embryonic lung and in basal epithelial cells of the cuboidal bronchial epithelium. Progressive invagination of the surface mesenchyme is associated with extensive branching of the airways, which are highly immunoreactive. In late gestation PRLR immunoreactivity predominates in the bronchial and bronchiolar epithelium and localizes to cells at the luminal surface.

We explored further the role of fetal mesenchyme through studies of the expression of PRLRs in developing skeletal muscles and bones. Fig. 10 shows sagittal sections of the tibia of a human fetus at $7.5 \mathrm{wk}$ of gestation. There is striking PRLR immunoreactivity in maturing chondrocytes, in the perichondrium, and in skeletal myocytes, shown below at higher magnification. Immunostaining in myocytes of the cardiac atria and ventricles (14 wk gestation) was also intense (data not shown).

The ontogenesis of PRLR expression in endochondral bones was examined in the fetal rat. Fig. 11 shows sagittal sections of the head of the rat embryo at 12.5-17.5 d of gestation. On embryonic day 12.5 , there is intense PRLR immunoreac-

\section{PRLR Expression in the Fetal Rat Lung}

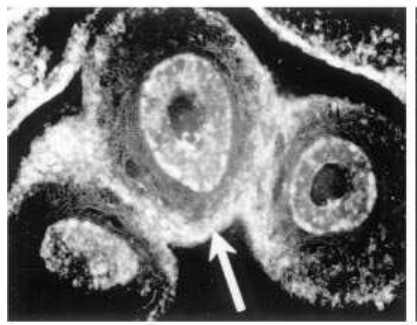

e 13.5

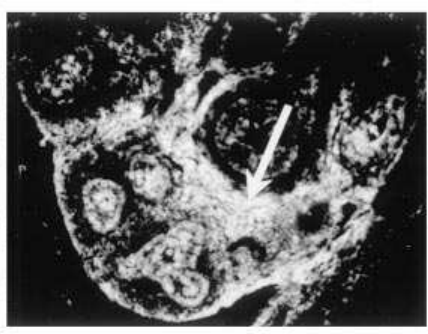

e 15.5

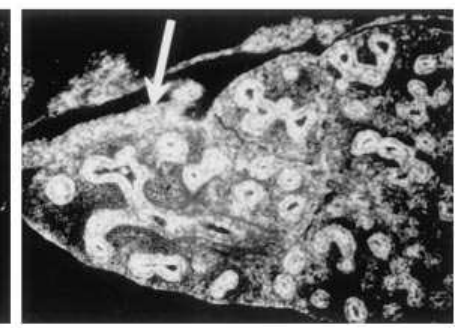

e 16.5
Figure 9. Ontogenesis of PRLR immunoreactivity in the fetal rat lung. Note the staining of the pulmonary mesenchyme (arrows) and the progressive increase in PRLR immunoreactivity during branching morphogenesis of the airway epithelium. Similar findings were noted in three separate experiments. $\times 100$. 


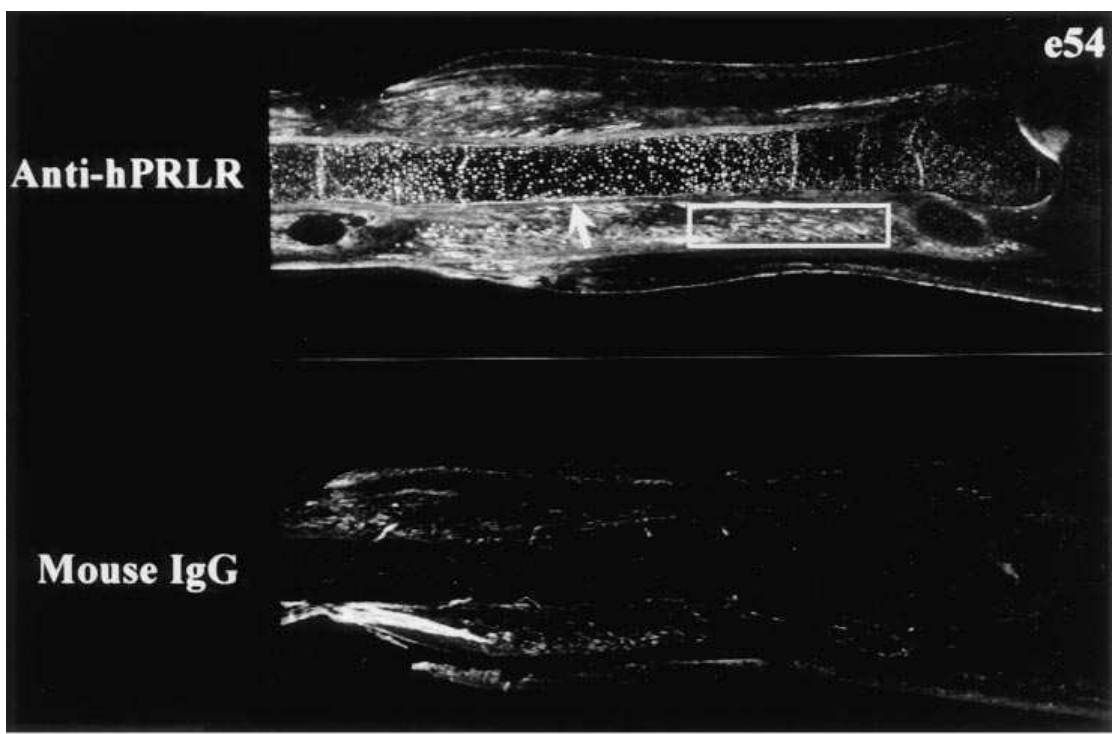

Skeletal Muscle

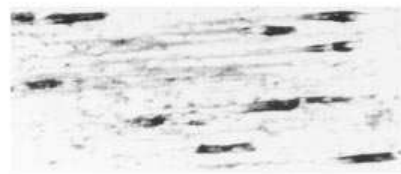

Figure 10. PRLR immunoreactivity in the human fetal tibia in early gestation (e54). Tissue sections were incubated with U5 $(50 \mu \mathrm{g} / \mathrm{ml})$ or with mouse IgG. Note the intense PRLR immunoreactivity in maturing chondrocytes, perichondrium (arrow), and skeletal myocytes, shown in the box $(\times 100)$ and in brightfield at higher magnification $(\times 200)$ below. Similar findings were noted in five separate experiments. tivity in the mesenchyme underlying the base of the brain. By day 15.5, this mesenchyme has begun to condense to form nodules of cartilage, and by day 17.5, the PRLR is expressed prominently in proliferating and maturing chondrocytes of the developing sphenoid and occipital bones. Interestingly, there is little PRLR immunoreactivity in late hypertrophic or calcified chondrocytes.

A similar pattern of expression is seen in the developing vertebral bones and ribs (Fig. 12). The PRLR is first expressed in mesenchymal cells that appear to migrate and surround the primordia of the vertebrae and ribs. Subsequently on days e16.5 through e18.5 there is intense expression in chondrocytes of the developing bones and in the fibrous intervertebral discs, which like vertebral cartilage are derived from somitic mesoderm. As in the bones of the limbs and the base of the skull, PRLR expression in the ribs and vertebrae appears to pre-

\section{PRLR Expression in Rat Craniofacial Bones}
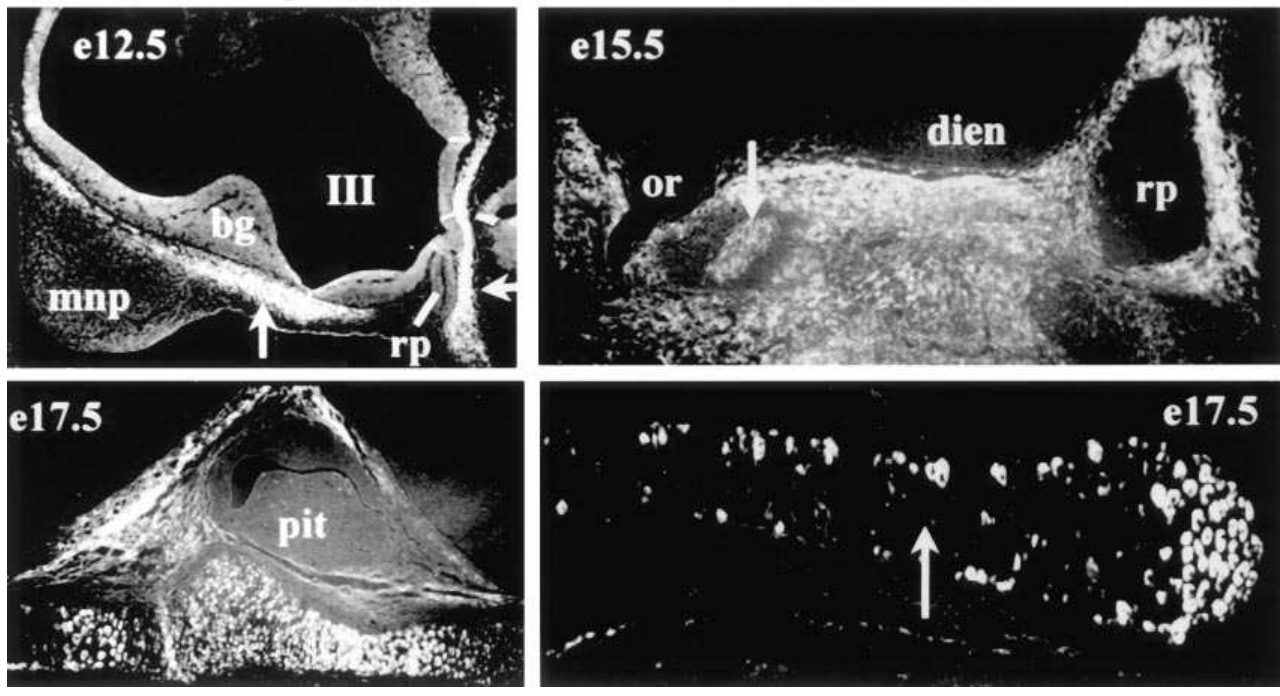

Figure 11. Ontogenesis of PRLR immunoreactivity in the rat craniofacial bones. Tissue sections were incubated with U5; control sections were immunonegative. On embryonic day e12.5, the PRLR is expressed in mesenchymal cells (arrows) underlying the base of the brain and in the interpeduncular fossa. mnp, medial nasal process; $r p$, Rathke's pouch; $b g$, basal ganglia. By day e15.5, this mesenchyme has begun to condense to form cartilage nodules (arrow). or, optic recess; dien, diencephalon; pit, pitutary. $2 \mathrm{~d}$ later (e17.5), PRLR immunoreactivity localizes primarily to maturing chondrocytes and to a lesser extent to proliferating chondrocytes (shown in the basisphenoid bone at $\times 100$ on the left and $\times 200$ on the right). There is a paucity of immunoreactivity in late hypertrophic and calcified chodrocytes (arrow). Similar findings were noted in six separate experiments. 


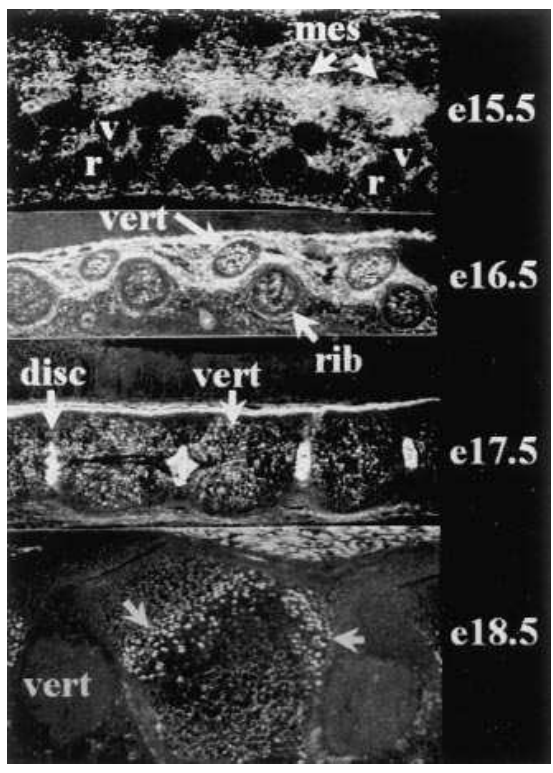

Figure 12. Ontogenesis of PRLR immunoreactivity in the rat vertebrae and ribs. Tissue sections were incubated with U5; control sections were immunonegative. The PRLR is first expressed (e15.5) in mesenchymal cells (mes) that surround the primordia of the vertebrae $(v)$ and ribs $(r)$. Subsequently there is intense PRLR immunoreactivity in maturing chondrocytes of the developing bones, seen most clearly on day e18.5 (arrows). Note also the reactivity in the mesodermal intervertebral disc. Similar findings were noted in four separate experiments. Magnification $\times 40$ except lower figure $\times 100$.

dominate in maturing chondrocytes rather than in terminally differentiated hypertrophic and mineralized chondrocytes.

\section{Discussion}

Our studies of the ontogenesis of PRLR expression in human and fetal rat tissues reveal a complexity of developmental and cell-specific changes that have not been appreciated previously. First, the relative expression of lactogen receptors in a single cell type may change markedly during a short period of time in early development. For example, the amount of PRLR immunoreactivity in human fetal hepatocytes increases two- to three-fold between 7.5 and 14 wk of gestation; similarly, there is a striking increase in PRLR immunoreactivity in fetal rat hepatocytes between days 16.5 and 17.5 of gestation.

Second, PRLRs in a single fetal tissue are expressed in multiple cell types derived from distinct embryonic germ layers. For example, PRLR immunoreactivity in the fetal duodenum is detected in villous epithelial cells, derived from embryonic endoderm, and basilar mesenchymal cells, derived from intermediate mesoderm. Similarly, the PRLR in the fetal lung is expressed in bronchiolar epithelial cells (endodermal) and pulmonary mesenchyme (mesodermal). Previous studies in the late gestational fetal rat $(15,16)$ demonstrated that the PRLR is also expressed in structures of ectodermal origin including the epidermis, whisker hair follicles, enamel epithelium, trigeminal ganglion, cochlear duct, the olfactory epithelium and the mitral and tufted cell neurons of the olfactory bulb.

Third, the distribution of PRLR expression among the different cell types in a single tissue may change dramatically dur- ing development. The pancreas and adrenal provide interesting examples. In the pancreas of the human adult and neonatal rat $(19,20)$ the PRLR is expressed preferentially or exclusively in islet cells, colocalizing with insulin and glucagon. In the human fetus and fetal rat in early gestation, however, the PRLR is expressed most intensely in pancreatic ductules and acinar cells; there is only little PRLR immunoreactivity in islet cells that express insulin and glucagon until late gestation. In the adrenal gland of the postnatal and pregnant rat $(21,22)$ and human adult (23), the PRLR is expressed throughout the cortex but most intensely in the zona reticularis. In the embryonic adrenal gland, on the other hand, the PRLR is first expressed in mesenchymal cells surrounding the adrenal primordium and then in a thin rim of mesenchymal and neocortical-like cells near the surface of the gland. By 14 wk of gestation in the human fetus, and by $20 \mathrm{~d}$ in the fetal rat, the PRLR is expressed throughout the fetal cortex.

The changes in the cellular distribution of expression of PRLRs in a single tissue during ontogeny predict changing roles for the lactogens in organ development and function. For example, in the mid-gestational fetal pancreas PRLRs are expressed in acinar tissue and ductal epithelial cells. This observation suggests a role for lactogens in the growth and function of the exocrine pancreas and possibly in the development of the islets, which arise from the pancreatic ducts (29). Subsequently in late gestation and in postnatal life the PRLR is expressed preferentially in islet cells, explaining the insulinotropic effects of lactogenic hormones in pancreatic islets from neonatal rats and mice and human adults (30-32).

In the embryonic adrenal gland, PRLRs are expressed initially in surface mesenchymal cells and neocortical cells. These cells have high mitotic activity and are thought to proliferate and migrate centripetally to populate the developing fetal cortex (33). The expression of PRLRs in surface mesenchymal and neocortical cells provides support for the hypothesis that lactogens play roles in adrenocortical maturation and/or growth during early fetal development. The subsequent emergence of lactogen receptors in differentiated adrenocortical cells provides a cellular mechanism through which lactogenic hormones may modulate the production of fetal adrenal androgens and glucocorticoids (23-26).

The expression of PRLRs in pulmonary mesenchymal cells and tubular epithelial cells during early development predicts novel roles for lactogens in the differentiation of the fetal lung. The fetal lung arises when tubular pockets of foregut endoderm invade mesenchymal cells derived from the splanchnic mesoderm (28). Initially the PRLR is expressed in the surface pulmonary mesenchyme and in basal epithelial cells, which divide rapidly and populate the developing airways. Extension of PRLR immunoreactivity into subcortical mesenchyme is accompanied by tubular growth and cytodifferentiation and branching of the airways, processes that require the direct interaction between mesenchymal and epithelial cells (28). In light of recent findings demonstrating that PRL induces branching morphogenesis in the mammary gland (34), it is tempting to speculate that lactogenic hormones may modulate the interactions between pulmonary mesenchyme and the branching pulmonary epithelium to facilitate lung development and growth. The expression of PRLRs in the airway epithelium may also provide a mechanism by which lactogenic hormones may, in concert with glucocorticoids, facilitate the production of surfactant in the human fetal lung $(35,36)$. 
Mesenchyme also gives rise to the fetal cartilage and skeletal muscle. Early in development the PRLR is expressed in abundance in mesenchymal tissue predestined to form the cartilage of the endochondral craniofacial and long bones, vertebrae, and ribs. With progression of fetal development, the PRLR localizes to maturing chondrocytes and, to a lesser extent, to chondrocytes in the proliferative zone of the cartilage growth plate. There is, however, little or no PRLR expression in late hypertrophic cartilage or in calcified bone cells. These observations suggest that lactogens may regulate preferentially the differentiation and maturation of cartilage rather than the function of terminally differentiated bone cells. Like maturing chondrocytes, the skeletal myocytes are highly immunoreactive during early fetal development. This finding is consistent with previous studies demonstrating anabolic effects of lactogenic hormones in isolated fetal myoblasts and fibroblasts (37-40).

The PRLR in the human fetus may serve as a binding protein for a number of lactogenic hormones that circulate in fetal serum. Human growth hormone and human placental lactogen, which bind the human PRLR with high affinity (41), are detected in human fetal serum as early as $8 \mathrm{wk}$ of pregnancy. Plasma concentrations of the two hormones may rise to levels as high as $35-500 \mathrm{ng} / \mathrm{ml}$ at mid-gestation $(2,4)$. Human fetal serum prolactin levels are relatively low (10-20 $\mathrm{ng} / \mathrm{ml})$ until the beginning of the third trimester, after which fetal prolactin levels rise progressively to a peak approximating $150 \mathrm{ng} / \mathrm{ml}$ at term (2). In the fetal rat, pituitary prolactin production does not begin until at or soon after the time of delivery (42-45) and rat growth hormone is a purely somatogenic hormone that does not bind to the PRLR. The predominant lactogen in the mid-late gestational rodent fetus appears to be placental lactogen II (PL II), which is detected in fetal serum as early as embryonic day e17 in the rat $(6,46)$ and day e16 in the mouse $(1)$. Like hPL and hGH, the rodent PLs bind with high affinity to PRLRs in fetal and maternal tissues and exert lactogenic effects in the mammary gland, ovary, and pancreas $(1,30,45)$.

Roles for the lactogens in the control of reproduction, lactation, immune function, electrolyte and mineral balance, and intermediary metabolism (47) have been established in studies conducted primarily in differentiated tissues from postnatal animals and human adults. However, our studies of the ontogenesis of PRLR expression in the early gestational human fetus and embryonic and fetal rat implicate new and complex roles for lactogens in organ development and function. The expression of PRLRs in derivatives of embryonic mesoderm in early gestation predicts novel roles for the lactogens in the differentiation and growth of the fetal adrenal, lung, small intestine, skeletal muscle, cartilage, and endochondral bones. Moreover, changes in the distribution of PRLRs in the pancreas and adrenal predict developmentally dependent changes in lactogenic function. Future studies should explore the mechanisms by which lactogens regulate tissue differentiation and growth during embryonic and fetal development and must define the factors that condition changes in the cellular distribution of lactogenic receptors during ontogeny.

\section{Acknowledgments}

The authors thank Samara Freemark, Melissa Eisenhauer, Julie Mason, and Kathleen Dittrich for their technical assistance.

These studies were supported by grants to M. Freemark from the
National Institutes of Child Health and Development (HD-24192) and Juvenile Diabetes Foundation (196029) and by grant HD00836-32 to the Central Laboratory for Human Embryology. Dr. Freemark is the recipient of a Research Career Development Award from the National Institutes of Child Health and Development.

\section{References}

1. Ogren, L., and F. Talamantes. 1988. Prolactins of pregnancy and their cellular source. Int. Rev. Cytol. 112:1-65.

2. Kaplan, S.L., M.M. Grumbach, and T.H. Shepard. 1972. The ontogenesis of human fetal hormones. I. Growth hormone and insulin. J. Clin. Invest. 51: 3080-3093.

3. Taylor, M.F., G. Jenkins, J.S. Robinson, G.D. Thorburn, H. Friesen, and J.S.D. Chan. 1980. Concentrations of placental lactogen in chronically catheterized ewes and fetuses in late pregnancy. J. Endocrinol. 85:27-34.

4. Hill, D.J., M. Freemark, A.J. Strain, S. Handwerger, and R.D.G. Milner. 1988. Placental lactogen and growth hormone receptors in human fetal tissues: relationship to fetal plasma human placental lactogen concentrations and fetal growth. J. Clin. Endocrinol. Metab. 66:1283-1290.

5. Duello, T.M., J.C. Byatt, and R.D. Bremel. 1987. The concentrations of bovine placental lactogen and the incidence of different forms in fetal cotyledons and in fetal serum. Domest. Anim. Endocrinol. 4:231-234.

6. Freemark, M., K. Kirk, C. Pihoker, M. Robertson, R. Shiu, and P. Driscoll. 1993. Pregnancy lactogens in the rat conceptus and fetus: circulating levels, distribution of binding, and expression of receptor messenger RNA. Endocrinology. 133:1830-1842.

7. Grumbach, M.M., and P.D. Gluckman. 1994. The human fetal hypothalamus and pituitary gland: the maturation of neuroendocrine mechanisms controlling the secretion of fetal pituitary growth hormone, prolactin, gonadotropins, adrenocorticotropic-related peptides and thyrotropin, In Maternal-Fetal Endocrinology. D. Tulchinsky and A.B. Little, editors. Saunders, Philadelphia, PA. 193-262.

8. Josimovich, J.B., K. Merisko, L. Boccela, and H. Tobon. 1977. Binding of prolactin by fetal rhesus cell membrane fractions. Endocrinology. 100:557-561.

9. Herington, A.C., J. Graham, and D.L. Healy. 1980 The presence of lactogen receptors in human chorion laeve. J. Clin. Endocrinol. Metab. 51:14661468 .

10. Freemark, M., A. Keen, J. Fowlkes, T. Mularoni, M. Comer, A. Grandis, and L. Kodack. 1992. The placental lactogen receptor in maternal and fetal sheep liver: regulation by glucose and role in the pathogenesis of fasting during pregnancy. Endocrinology. 130:1063-1070.

11. Fowlkes, J., and M. Freemark. 1993. Placental lactogen binding sites in isolated fetal fibroblasts: characterization, processing and regulation. Endocrinology. 132:2477-2483.

12. Shepard, T.H. 1993. Developmental pathology of the embryonic and previable fetal periods. In Neonatal Physiology and Treatment, 4th edition, G.B. Avery and M.A. Fletcher, editors. Lippincott, Philadelphia, PA. 109-125.

13. Boutin, J.M., M. Edery, M. Shirota, C. Jolicoeur, L. Lesueur, S. Ali, D. Gould, J. Djiane, and P.A. Kelly. 1989. Identification of a cDNA encoding a long form of prolactin receptor in human hepatoma and breast cancer cells. Mol. Endocrinol. 203:1455-1461.

14. Sanger, F., S. Nicklen, and A.R. Coulson. 1977. DNA sequencing with chain terminating inhibitors. Proc. Natl. Acad. Sci. USA. 74:5463-5467.

15. Royster, M., P. Driscoll, J. Andrews, P.A. Kelly, and M. Freemark 1995. The prolactin receptor in the fetal rat: cellular localization of messenger RNA, immunoreactive protein and ligand binding activity and induction of expression in late gestation. Endocrinology. 136:3892-3900.

16. Freemark, M., P. Driscoll, J. Andrews, P.A. Kelly, and M. Royster. 1996. Ontogenesis of prolactin receptor gene expression in the rat olfactory system: potential roles for lactogenic hormones in olfactory development. Endocrinology. 137:934-942.

17. Okamura, H., J. Zachwieda, S. Raguet and P.A. Kelly. 1989. Characterization and application of monoclonal antibodies to the prolactin receptor. Endocrinology. 1254:2499-2508.

18. Lochnan, H.A., H. Buteau, S. Richards, M. Edery, and P.A. Kelly. 1995 Functional activity of the human prolactin receptor and its ligands. Mol. Cell. Endocrinol. 114:91-99.

19. Sorenson, R.I., and L.E. Stout. 1995. Prolactin receptors and JAK 2 in islets of Langerhans: an immunohistochemical analysis. Endocrinology. 136: 4092-4098.

20. Garcia-Caballero, T., G. Morel, R. Gallego, M. Fraga, E. Pintos, D. Gago, B.K. Vonderhaar, and A. Beiras. 1996. Cellular distribution of prolactin receptors in human digestive tissues. J. Clin. Endocrinol. Metab. 81:1861-1866.

21. Freemark, M.F., K. Kirk, and M.C. Robertson. 1994. Cellular distribution of placental lactogen binding sites in the pregnant rat. Endocrine. 2:199-205.

22. Nagano, M., and P.A. Kelly. (1994). Tissue distribution and regulation of rat prolactin receptor gene expression. J. Biol. Chem. 269:13337-13345.

23. Glasow, A., M. Breidert, A. Haidan, U. Anderegg, P.A. Kelly, and S.R. Bornstein. 1996. Functional aspects of the effect of prolactin on adrenal ste- 
roidogenesis and distribution of the prolactin receptor in the human adrenal gland. J. Clin. Endocrinol. Metab. 81:3103-3111.

24. Ogle, T.F., and J.I. Kitay. 1979. Interactions of prolactin and adrenocorticotropin in regulation of adrenocortical secretion in the female rat. Endocrinology. 104:40-44.

25. Eldridge, J.C., and J.R. Lymangrover. 1984. Prolactin stimulates and potentiates adrenal steroid secretion in vitro. Horm. Res. (Basel). 20:252-260.

26. Pepe, G.J., and E.D. Albrecht. 1990. Regulation of the primate fetal adrenal cortex. Endocr. Rev. 11:151-176.

27. Neiss, W.F. 1982. Morphogenesis and histogenesis of the connecting tubule in the rat kidney. Anat. Embryol. 165:81-95.

28. Shannon, J.M. 1994. Induction of alveolar type II cell differentiation in fetal tracheal epithelium by grafted distal lung mesenchyme. Dev. Biol. 166: $600-614$.

29. Le Douarin, N.M. 1988. On the origin of pancreatic endocrine cells. Cell. 53:169-171.

30. Brelje, T.C., D.W. Scharp, P.E. Lacy, L. Ogren, F. Talamantes, M. Robertson, H. Friesen, and R. Sorenson. 1993. Effect of homologous placental lactogen, prolactins, and growth hormones on islet b-cell division and insulin secretion in rat, mouse, and human islets: implicaton for placental lactogen regulation of islet function during pregnancy. Endocrinology. 132:879-887.

31. Sekine, N., U. Ullrich, R. Regazzi, W.-F. Pralong, and C.B. Wollheim. 1996. Postreceptor signalling of growth hormone and prolactin and their effects in the differentiated cell line, INS-1. Endocrinology. 137:1841-1850.

32. Weinhaus, A.J., L.E. Stout, and R.L. Sorenson. 1996. Glucokinase, hexokinase, glucose transporter 2 and glucose metabolism in islets during pregnancy and prolactin-treated islets in vitro: mechanisms for long term up-regulation of islets. Endocrinology. 137:1640-1649.

33. Mesiano, S., C.L. Coulter, and R.B. Jaffe. 1993. Localization of cytochrome P450 cholesterol side-chain cleavage, 17 alpha hydroxylase/17,20-lyase, and 3 beta hydroxysteroid dehydrogenase isomerase steroidogenic enzymes in human and rhesus monkey fetal adrenal glands: reappraisal of functional zonation. J. Clin. Endocrinol. Metab. 77:1184-1189.

34. Darcy, K.M., S.F. Shoemaker, P.P. Lee, M.M. Vaughan, J.D. Black, and M.M. Ip. 1995. Prolactin and epidermal growth factor regulation of the proliferation, morphogenesis, and functional differentiation of normal rat mammary epithelial cells in three dimensional primary culture. J. Cell. Physiol. 163:346-364.

35. Mendelson, C.R., J.M. Johnston, P.C. MacDonald, and J.M. Snyder. 1981. Multihormonal regulation of surfactant synthesis by human fetal lung in vitro. J. Clin. Endocrinol. Metab. 53:307-317.

36. Nguyen, T.M., H. Guillozo, L. Marin, M.E. Dufour, C. Tordet, J.W.
Pike, and M. Garabedian. 1990. 1,25-dihydroxyvitamin D3 receptors in rat lung during the perinatal period: regulation and immunohistochemical localization. Endocrinology. 127:1755-1762.

37. Adams, S.O., S.P. Nissley, S. Handwerger, and M.M. Rechler. 1983. Developmental patterns of insulin-like growth factor I and II synthesis and regulation in rat fibroblasts. Nature (Lond.). 302:150-152.

38. Freemark, M., and S. Handwerger. 1984. Ovine placental lactogen, but not growth hormone, stimulates amino acid transport in fetal rat diaphragm. Endocrinology. 112:402-404

39. Hill, D., C. Crace, and R. Milner. 1985. Incorporation of ${ }^{3} \mathrm{H}$-thymidine by isolated human fetal myoblasts and fibroblasts in response to human placental lactogen: possible mediation of hPL action by release of immunoreactive SM-C. J. Cell. Physiol. 125:337-344.

40. Hill, D.J., C.J. Crace, A.J. Strain, and R.D.G. Milner. 1986. Regulation of amino acid uptake and deoxyribonucleic acid synthesis in isolated human fetal fibroblasts and myoblasts: effect of human placental lactogen, somatomedin-C, multiplication-stimulating activity, and insulin. J. Clin. Endocrinol. Metab. 62:753-760.

41. Lowman, H.B., B.C. Cunningham, and J.A. Wells. 1991. Mutational analysis and protein engineering of receptor-binding determinants in human placental lactogen. J. Biol. Chem. 266:10982-10988.

42. Reusens, B., E. Kuhn, and J. Hoet. 1979. Fetal plasma prolactin levels and fetal growth in relation to maternal CB-154 treatment in the rat. Gen. Comp. Endocrinol. 39:118-120.

43. Slabaugh, M.B., M.E. Lieberman, J.J. Rutledge, and J. Gorski. 1982. Ontogeny of growth hormone and prolactin gene expression in mice. Endocrinology. 110:1489-1497.

44. Khorram, O., L.R. Depalatis, and S.M. McCann. 1984. Hypothalamic control of prolactin secretion during the perinatal period in the rat. Endocrinology. 115:1698-1704.

45. Soares, M.J., T.N. Faria, K.F. Roby, and S. Deb. 1991. Pregnancy and the prolactin family of hormones: coordination of anterior pituitary, uterine, and placental expression. Endocr. Rev. 12:402-423.

46. Kishi, K., M. Hirashiba, and Y. Hasegawa. 1991. Gestational profiles of rat placental lactogen II and growth hormone in maternal and fetal serum, amniotic fluid and placental tissue. Endocrinol. Jpn. 38:589-595.

47. Nicoll, C.S., and H.A. Bern. 1972. On the actions of PRL among the vertebrates: is there a common denominator? In Lactogenic Hormones. G.E.W. Wolstenholme and J. Knight, editors. Churchill Livingstone, London, Edinburgh, UK. 299-337. 